\title{
¿Es posible conservar una Salamanca? Reflexiones sobre arqueología, conservación y usos locales del patrimonio desde una cueva con arte rupestre de Catamarca
}

\section{Lucas Gheco, ${ }^{1}$ Melisa Rodríguez Oviedo, ${ }^{2}$ Marcos Gastaldi 3 y Marcos Quesada ${ }^{4}$}

1 Instituto de Investigaciones sobre el Patrimonio Cultural (IIPC-UNSAM), Buenos Aires, Argentina. Centro de Investigaciones y Transferencia Catamarca (CONICET-UNCa), Prado 366, Catamarca, Argentina. (iD) https://orcid.org/oooo-0003-4941-1196

Correo electrónico: gheco@hotmail.com

2 Instituto de Antropología de Córdoba (IDACOR - CONICET), Av. Irigoyen 174, Córdoba, Argentina. Museo de Antropología (UNC), Av. Irigoyen 174, Córdoba, Argentina.

Correo electrónico: melisa.roviedo@gmail.com

3 Instituto de Antropología de Córdoba (IDACOR - CONICET), Av. Irigoyen 174, Córdoba, Argentina. Museo de Antropología (UNC), Av. Irigoyen 174, Córdoba, Argentina.

Correo electrónico: mrgastaldi@gmail.com

4 Centro de Investigaciones y Transferencia Catamarca (CONICET-UNCa), Prado 366, Catamarca, Argentina. Escuela de Arqueología, Universidad Nacional de Catamarca. Maestro Quiroga 8o, San Fernando del Valle de Catamarca, Catamarca, Argentina

(iD) https://orcid.org/oooo-0002-0533-2894

Correo electrónico: mkesada@yahoo.com.ar
Recibido:

15 de abril de 2021

Aceptado:

8 de septiembre de 2021

doi: $10.34096 /$ runa.v43i1.10063

\section{Resumen}

Este trabajo describe y analiza una experiencia etnográfica extraordinaria en el marco de un relevamiento arqueológico en una cueva con arte rupestre ubicada en la provincia de Catamarca del Noroeste argentino. Dicho abrigo rocoso es considerado, por un lado, como un sitio arqueológico con valor patrimonial; pero es también una potente salamanca, evento/lugar de adquisición de dones extraordinarios mediante pactos diabólicos. Frente a este caso de estudio paradigmático, nos preguntamos: ¿es posible conservar una salamanca? A partir de dicho interrogante y de nuestra particular experiencia al visitar la cueva, este trabajo tiene como objetivo discutir y reflexionar sobre los alcances, tensiones y disputas en torno a las nociones de patrimonio y conservación, pero también sobre las afectaciones en el trabajo de campo. ¿Cómo deberíamos actuar, en tanto arqueólogos, frente a las implicancias legales de proteger el "sitio arqueológico"? ¿Es posible conciliar dichas acciones de conservación/ restauración con los usos actuales de la cueva? ¿En qué medida el abrigo es solo un "sitio arqueológico"? Enredados en estas preguntas, a lo largo de este ensayo presentamos algunos puntos problemáticos en donde se anudan la conservación, la arqueología y los usos locales del patrimonio.
Palabras clave

Patrimonio; Conservación; Arte Rupestre; Perspectivismo; Salamanca; Arqueología 


\title{
Is it possible to conserve a salamanca? Reflections about archaeology, conservation and local uses of heritage from a cave with rock art in Catamarca
}

\begin{abstract}
This work describes and analyzes an extraordinary ethnographic experience within the framework of an archaeological survey of a cave with rock art located in the province of Catamarca, northwestern Argentina. This rocky shelter is considered, on the one hand, as an archaeological site with patrimonial value; but it is also a powerful salamanca, event / place of acquisition of extraordinary gifts through diabolical pacts. Faced with this paradigmatic study case, we ask ourselves: is it possible to conserve a salamanca? Based on this question and our particular experience visiting the cave, this paper aims to discuss and reflect about the scopes, tensions and disputes around notions of heritage and conservation, but also on the affects produce in fieldworks. How should we act, as archaeologists, in relation with the legal implications of protecting the "archaeological site"? Is it possible to reconcile such conservation/restoration actions with the current uses of the cave? Is the shelter only an "archaeological site"? In the course of this essay, we present some problematic points where conservation, Archaeology and local uses of heritage meet.
\end{abstract}

Key Words

Heritage; Conservation; Rock art; Perspectivism; Salamanca; Archaeology

\section{É possível conservar uma salamanca? Reflexões sobre arqueo- logia, conservação e usos locais do patrimônio de uma caver- na com arte rupestre de Catamarca}

\section{Resumo}

Palavras-chave

Patrimônio; Conservação; Arte rupestre; Perspectivismo; Salamanca; Arqueologia
Este trabalho descreve e analisa uma extraordinária experiência etnográfica no âmbito de um levantamento arqueológico em uma caverna com arte rupestre localizada na província de Catamarca, no noroeste da Argentina. Este abrigo rochoso é considerado, por um lado, como um sítio arqueológico de valor patrimonial; mas também é uma salamanca poderosa, evento / local de aquisição de dons extraordinários através de pactos diabólicos. Diante desse estudo de caso paradigmático, nos perguntamos: é possível manter uma Salamanca? Com base nessa questão e na nossa experiência particular de visita à caverna, este trabalho tem como objetivo discutir e refletir sobre a abrangência, tensões e disputas em torno das noções de patrimônio e conservação, mas também sobre os efeitos no trabalho de campo. Como devemos agir, como arqueólogos, diante das implicações jurídicas da proteção do "sítio arqueológico"? É possível conciliar essas ações de conservação / restauração com os usos atuais da caverna? Até que ponto o abrigo é apenas um "sítio arqueológico"? Envolvidos nessas questões, ao longo deste ensaio apresentamos alguns pontos problemáticos onde se cruzam a conservação, a arqueologia e os usos locais do patrimônio.

\section{Introducción}

El objeto de este trabajo -difícilmente caracterizable como un mero objeto- es una cueva con arte rupestre en la provincia de Catamarca (noroeste argentino). 
Pero no cualquier cueva o, mejor dicho, no solo una cueva sino también una "salamanca": evento/lugar de adquisición de dones extraordinarios mediante pactos con el mismísimo demonio; acontecimiento/espacio ampliamente documentado en esta región del país y, por lo general, interpretado como parte del "folklore tradicional" (Farberman, 2005; Escolar, 2012; Biasatti, 2016). En este abrigo, además de las "pinturas arqueológicas", los restos materiales de actividades modernas otorgan algunas pistas sobre sus usos actuales: paredes repletas de nombres pintados, restos de velas quemadas, cráneos de chivos acomodados en una especie de altar y hasta una leyenda escrita que afirma sin rodeos: "Ponga su nombre y entrege [sic] su alma. 666". Frente al carácter complejo de esta cueva, a la vez "sitio arqueológico" y "salamanca", nos preguntamos: ¿cómo deberíamos actuar, en tanto arqueólogos, frente a las implicancias legales de proteger el "sitio"? ¿Es posible conciliar dichas acciones de conservación/restauración con los usos actuales de la cueva? ¿Hasta qué punto dichas intervenciones no limitarían el carácter de "salamanca"? ¿En qué medida la inacción estatal pondría en riesgo el "sitio arqueológico"? Enredados en estas preguntas, a lo largo de este ensayo presentamos algunos puntos problemáticos en donde se anudan la conservación, la arqueología y los usos locales del patrimonio.

En las próximas secciones se describen, en primer lugar, las principales características de la salamanca de Albigasta a partir de nuestra particular experiencia al visitarla. Luego, combinando los comentarios recogidos durante los trabajos de campo con las diversas publicaciones que han estudiado las salamancas, delineamos algunos puntos que permiten sintetizar la multiplicidad de variantes con que ha sido definido este espacio/fenómeno/evento. Con posterioridad, describimos dos perspectivas en pugna que expresan comprensiones ontológicas distintas, y en algún punto contrapuestas, de la cueva, con las consecuentes tensiones al momento de diagramar los trabajos de conservación/restauración. De este modo, esperamos avanzar en la comprensión de los límites, posibilidades y efectos de las acciones académicas y estatales emprendidas en pos de la conservación de los sitios arqueológicos mediante un ejemplo que, por sus características particulares, magnifica las tensiones que usualmente se presentan en los procesos de patrimonialización (Prats, 2005). Como veremos, dichos procesos no representan el reconocimiento de las características innatas o esenciales de determinados objetos y lugares de valor excepcional, sino instancias de negociación política a través de las cuales el patrimonio es creado (Bendix, 2009; Smith, 2011).

\section{La salamanca de Albigasta}

La sierra de El Alto-Ancasti, en el extremo sudeste de la provincia de Catamarca, es reconocida a nivel internacional por sus numerosos sitios arqueológicos con arte rupestre prehispánico (Schobinger y Gradin, 1983). Hasta el momento, luego de medio siglo de estudios en la zona, fueron documentados más de un centenar de abrigos con grabados y/o pinturas rupestres (Gheco, 2017). En términos generales, dichos sitios fueron asociados a la Cultura de La Aguada (600-900 d.C.) a partir de las similitudes estilísticas apreciadas entre varias de las pinturas rupestres y los diseños de la cerámica atribuida a dicha cultura (Segura, 1971, 1988; De la Fuente y Arrigoni, 1975; De la Fuente, 1979; Gramajo y Martínez Moreno, 1982; González, 1998; Hedges et al., 1998; Llamazares, 1999; De la Fuente, Nazar y Pelli, 2005; Nazar, Gheco y Barot, 2012; Nazar, De la Fuente, Gheco, 2014). 
Sin embargo, otras investigaciones han destacado una mayor extensión cronológica del arte rupestre de El Alto-Ancasti y su carácter más heterogéneo. Una de las especialistas locales más prolífica en este tema fue Amalia Gramajo. Junto con su esposo, Hugo Martínez Moreno, relevaron varios sitios de la zona entre las décadas de 1960 y 1990 (Gramajo y Martínez Moreno, 1978, 1982). En una reseña sobre la historia del departamento El Alto -una de las mayores jurisdicciones políticas en la sierra-, la autora menciona distintos abrigos con arte rupestre y los asigna a diferentes períodos prehispánicos e, incluso, coloniales (Gramajo, 2001). Varios de estos sitios, como Oyola, Los Algarrobales y La Aguadita, fueron objeto de nuevos relevamientos en los últimos años (Nazar et al., 2012; Bocelli, 2016; Quesada, Zuccarelli, Gheco, Gastaldi y Boscatto, 2016; Gordillo, Zuccarelli y Eguía, 2017; Gheco, 2020). Otros fueron menos explorados y su conocimiento es muy escaso, entre ellos la salamanca de Albigasta.

Desde hace casi una década que estudiamos el pasado prehispánico de la sierra, con especial énfasis en el arte rupestre (Quesada y Gheco, 2011). Entre las tareas desarrolladas, el relevamiento de los sitios -incluso de aquellos registrados parcialmente décadas atrás- ha sido uno de los trabajos fundamentales. Fue en el marco de dichas actividades que intentamos llegar a la Salamanca descripta por Gramajo (2001) en proximidades de las localidades de Albigasta (Catamarca) y Frías (Santiago del Estero). Luego de varios intentos fallidos, una siesta de diciembre de 2013 alcanzamos la cueva. Fuimos varios, unas once personas, aprovechando que estábamos participando del primer Taller de Arqueología de la Sierra de Ancasti y zonas aledañas (TASA, 2013) en Tapso, a pocos kilómetros al norte de Albigasta. No era la primera vez que íbamos a una cueva mencionada por los pobladores de la zona como salamanca. Otros abrigos donde habíamos trabajado también son, además de sitios con arte rupestre, espacios peligrosos referidos localmente como salamancas, como por ejemplo la cueva de La Candelaria y Oyola 7. Sin embargo, en esta ocasión, nuestra experiencia al visitarla fue bastante distinta.

Al emprender el camino no sabíamos dónde estaba la cueva más allá del nombre del poblado cercano, por lo que al llegar a Albigasta comenzamos a preguntar por ella. Entre respuestas esquivas y luego de varias consultas, nos indicaron que estaba río arriba, aunque sin mayores precisiones que la siguiente referencia: "Está en un lugar donde hay muchos cuervos". Quienes sabían de la existencia de la cueva decían no conocerla personalmente y, por lo tanto, no estar al tanto del camino. Llegamos al río Albigasta, dejamos los tres autos y comenzamos a caminar por el cauce seco, sin rumbo preciso más allá del ascenso indicado. La situación no era muy alentadora: caminábamos por el lecho arenoso del río en medio de una siesta calurosa, una franja de monte espinoso flanqueaba el curso en ambos márgenes y luego, a cada lado, se alzaban paredes rocosas verticales que iban encajonando cada vez más nuestro sendero. Continuamos andando un rato hasta que vimos, a unos cien metros, una persona que caminaba por el río en dirección opuesta. Lo saludamos a la distancia e intentamos hablar con él. Se detuvo a unos cincuenta metros y nos esperó parado al lado de un esqueleto vacuno, con un rifle sobre el hombro. Nos presentamos y le preguntamos por la salamanca. Luego de algunas palabras, nos indicó que no habíamos tomado el camino correcto, que la cueva que conocía estaba a varios kilómetros de distancia, y que convenía retornar a los vehículos y trasladarnos hacia otro punto río arriba. Con el calor agobiante de la siesta, no necesitábamos muchos argumentos para convencernos de irnos. Sin embargo, mientras nos despedíamos para comenzar el regreso, su discurso giró abruptamente y nos preguntó: “¿Por qué no caminan un poco más? Si ya 
están acá ¿por qué no siguen?". Y nuevamente nos convenció. Lo saludamos y continuamos río arriba, otra vez sin rumbo.

Luego de girar en uno de los tantos meandros del Albigasta, observamos a tres chicos que parecían estar jugando en medio del cauce del río, en unos pequeños charcos de agua que aún sobrevivían sobre la arena caliente. Llegamos hasta ellos y reiteramos nuestra pregunta por la salamanca. Decidieron llevarnos; era, nos decían, más adelante. Caminamos un rato hasta que decidieron quedarse, en otro charco, y que siguiéramos solos. El camino indicado parecía sencillo, aunque sin grandes precisiones: debíamos caminar por el río hasta llegar a un alambrado, "ahí entrar en el monte y listo". Seguimos. Unos minutos después, luego de otra curva del cauce, vimos el alambrado que cruzaba perpendicular al río. Al llegar, notamos que justo donde el alambrado se perdía en el monte, una senda interrumpía la vegetación y se dirigía a un alto acantilado sobre el cual giraba una numerosa bandada de jotes. Continuamos unos minutos por el camino de herradura hasta un par de grandes rocas con algunos grabados rupestres. Pensamos que podía tratarse del sitio descripto por Gramajo, aunque no había ninguna cueva. Mientras algunos documentaban los motivos, otros decidieron continuar por la senda hasta el paredón vertical que flanqueaba el río por el norte. Luego de unos minutos, divisamos allí la cueva. Es una gran grieta a modo de hendidura que penetra en una pared rocosa de unos veinticinco o treinta metros de altura. Su ancho máximo no supera los diez metros y su profundidad se pierde en la oscuridad. A la distancia, en el acceso a la cueva, un escrito en pintura blanca hace las veces de un escueto instructivo: "Ponga su nombre y entrege [sic] su alma" (Figura 1).

Figura 1. A. Vista del exterior de la salamanca de Albigasta. B. Detalle de algunos escritos dispuestos en la pared que da al este del abrigo. C. Cráneos de chivos ubicados en las grietas e irregularidades de la pared este de la cueva. D. Detalle de algunos escritos de nombres, superpuestos y elaborados con distintos colores.

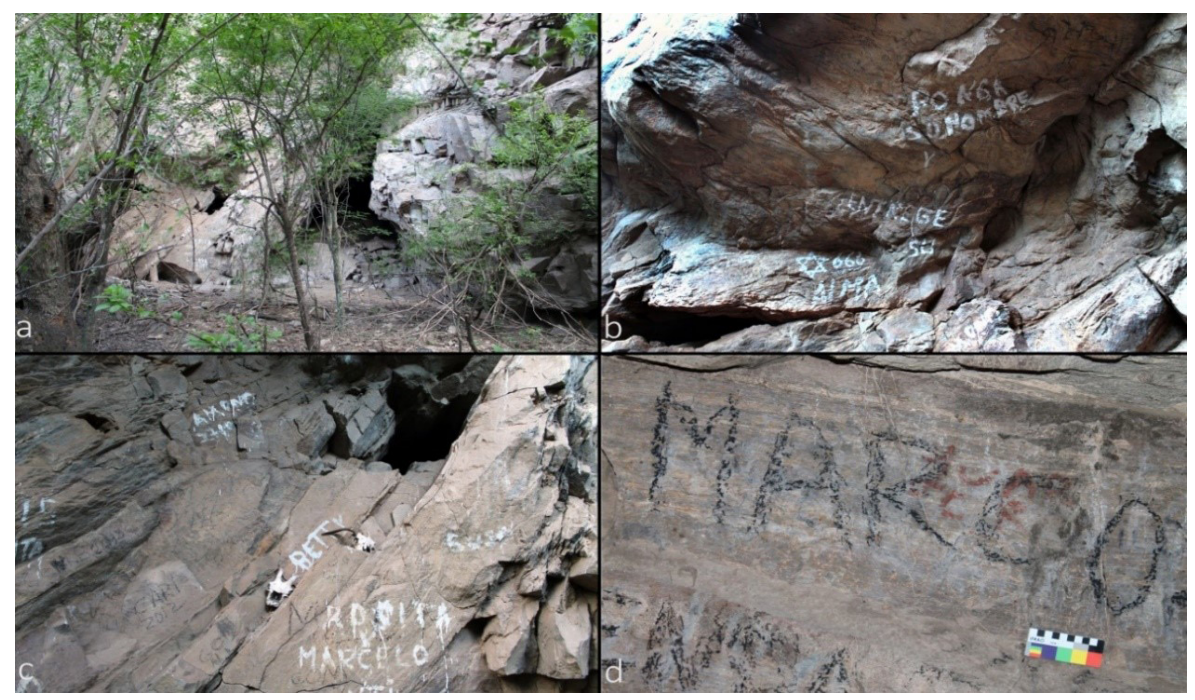

A cada lado, las paredes de la gran grieta presentan nombres escritos con pinturas distintas, colores diferentes, instrumentos disímiles. Algunos están superpuestos y otros, desleídos, apenas llegan a observarse. Unos metros más arriba, sobre la pared oeste, una serpiente pintada en color negro recuerda a los motivos prehispánicos relevados en otros sitios de la zona. Justo frente a ella, pero en la pared opuesta, algunas figuras del mismo color parecen remitir 
a camélidos. La tonalidad negra, el ancho del trazo, el estado de conservación y la ubicación elevada distinguen a estas pinturas de los escritos modernos y nos permiten sospechar de su mayor antigüedad (Figura 2).

Figura 2. A. Detalle del motivo serpentiforme. B. Fotografía procesada con D-Stretch (YBK) para resaltar los colores negros. C. Detalle de un conjunto de motivos negros superpuestos a una figura antropomorfa. D. Fotografía procesada con D-Stretch (YBK) para resaltar los colores negros.

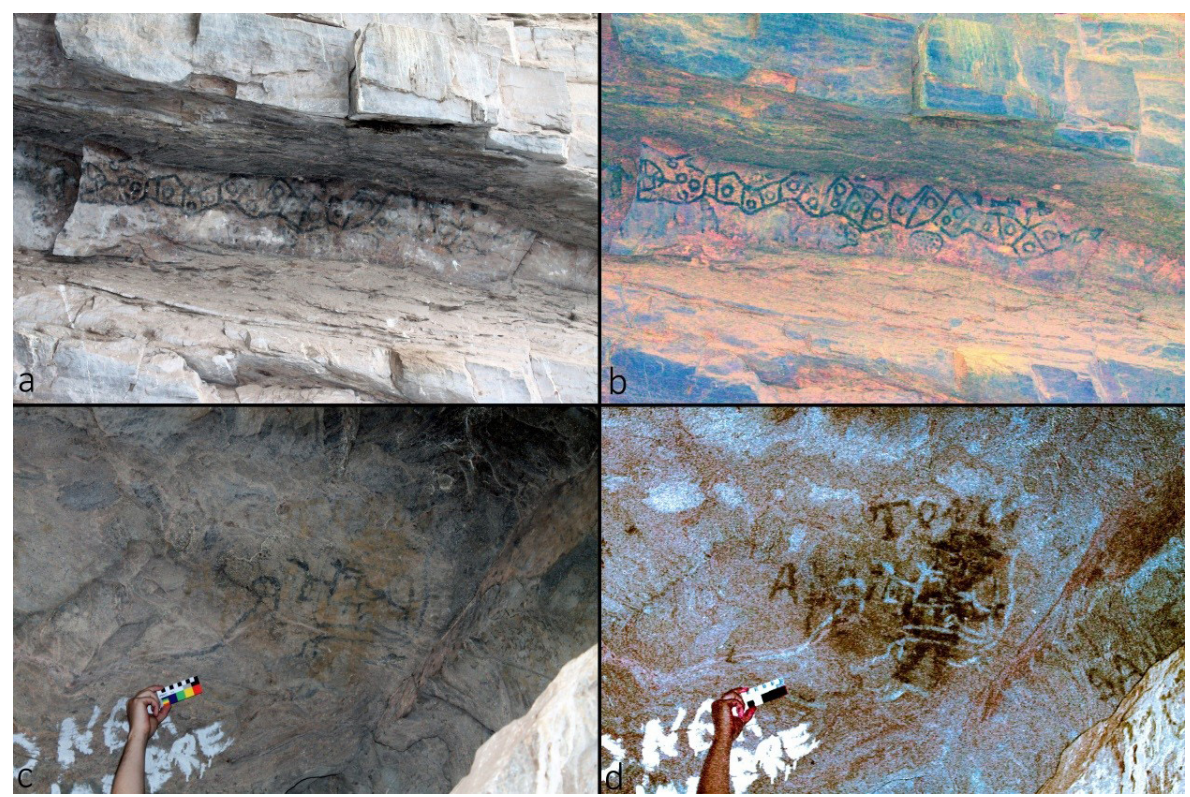

Luego de realizar una primera recorrida por la cueva, comenzamos un rápido relevamiento fotográfico. A los pocos minutos, varias de las cámaras utilizadas comenzaron a fallar. Al momento de tomar la imagen, intentaban hacer foco pero no lo lograban y, luego de varias pruebas, se apagaban. A pesar de los reiterados intentos y de cambiar las baterías, dos cámaras no pudieron ser más utilizadas. Pero quedaban otras, así que continuamos con la documentación.

Unos minutos más tarde decidimos revisar las fotos que habíamos tomado. Mientras repasábamos las imágenes desde el display de las cámaras que aún funcionaban, notamos que en ellas aparecían, dentro de un conjunto de nombres, los nuestros: Marcos, Vero, Marcos, etc. Y también el apellido de uno de los presentes: Burgos. Conversábamos sorprendidos sobre la situación, sobre las cámaras que fallaban y los nombres en las fotos y en las paredes, cuando dos sonidos secos llamaron nuestra atención. Parecían los sonidos del impacto de dos piedras relativamente grandes caídas desde lo alto del farallón rocoso, donde se hunde la cueva hacia la franja de monte que la separa del lecho seco del Albigasta.

Esos sonidos extraños nos hicieron olvidar de los nombres en las fotos y, aún más, de buscar sus correlatos materiales entre las distintas inscripciones en las paredes. Decidimos iniciar el regreso para no llegar de noche a Tapso. Salimos de la cueva, atravesamos el monte y alcanzamos el río. Caminábamos de a dos o tres, por momentos, pensativos, mientras probábamos tomar fotos con las cámaras que habían fallado. Ahora todo parecía andar bien (Figura 3). Luego de un rato de caminar llegamos a los autos, uno de los cuales tenía el vidrio roto del lado del acompañante. Algunos compartimentos parecían 
haber sido forzados, pero no faltaba nada. Con un plástico y cinta adhesiva sellamos -como pudimos- la ventana faltante y salimos de regreso hacia Tapso.

Uno de los autos, en donde viajaban dos de los autores de este trabajo (LG y MG), se demoró y partió un par de minutos después por el único camino rural que conducía al río. A los pocos metros de iniciar el viaje, divisamos a un jinete a caballo que venía en dirección opuesta. Detuvimos el auto e intentamos hacerle señas para preguntarle si había observado alguna persona cerca de los vehículos cuando no estábamos. El jinete pasó a escasos metros del auto, pero no registró nuestros saludos, como si no nos hubiera visto. Seguimos hacia Tapso y llegamos a la hostería. Unas horas más tarde, mencionamos esta situación con quienes viajaban en los autos que habían salido antes por el mismo camino. Ninguno recordaba haber visto un jinete.

Figura 3: Fotografía tomada mientras regresábamos de la salamanca de Albigasta, con una de las cámaras que había dejado de funcionar en la cueva.Salamancas, cuevas y pinturas

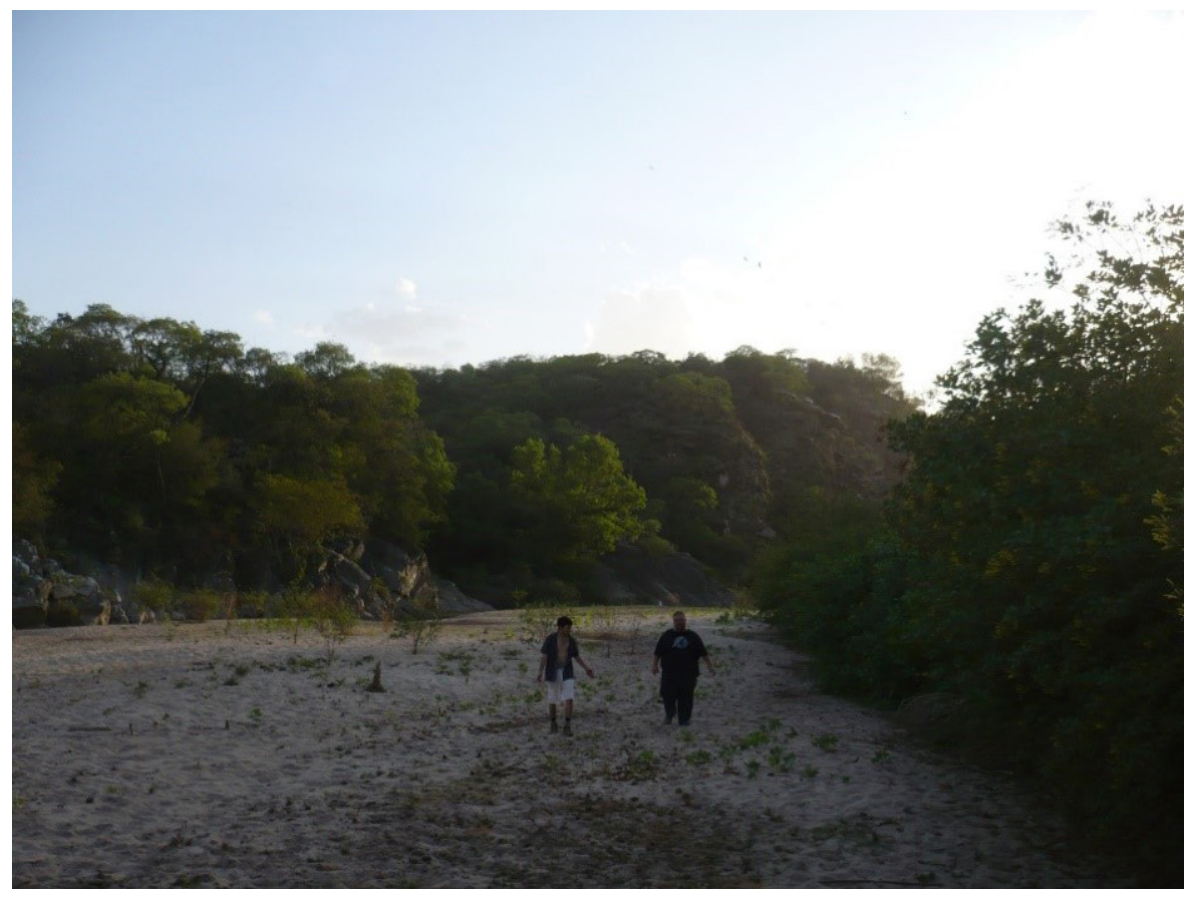

Evento fantasmal, espacio de transmisión de conocimientos y dones extraordinarios, fiesta del diablo, escuela de los indios, universidad de las hechiceras, lugar de pactos con el demonio, etc. Esas son solo algunas de las formas en que han sido definidas las salamancas, un evento en sí mismo difícilmente caracterizable, pero cuyos rastros se extienden en gran parte de América Latina, particularmente en Chile y Argentina (Escolar, 2012). Distintos antropólogos e historiadores han desarrollado extensos trabajos para intentar aprehenderlas, indagar en sus orígenes, transformaciones y roles actuales (Farberman, 2005; Escolar, 2012; Biasatti, 2016). No es nuestra intención discutir dichas investigaciones, sino retomar un conjunto de definiciones y sumarlas a algunas de nuestras experiencias y conversaciones desarrolladas a lo largo de las estadías en los distintos pueblos de la sierra; conversaciones informales bastante lejanas a una investigación antropológica sistemática, pero en las cuales, sin quererlo, nos topamos una y otra vez con las salamancas y, en particular, con la Salamanca 
de Albigasta. A los intereses de este artículo y sin desconocer la multiplicidad de variantes de este fenómeno, son tres las características que nos interesa destacar.

En primer lugar, las salamancas se presentan como espacios subversivos y clandestinos al orden establecido. Fueron y son lugares apartados de los centros poblados; peligrosos y secretos para quienes no se hayan iniciado. Ya sea en las actas coloniales de los juicios por brujería en Santiago del Estero (Farberman, 2005) como en los registros antropológicos actuales (Biasatti, 2016), las salamancas aparecen como espacios contrahegemónicos, donde se "aprenden" conocimientos y capacidades extraordinarias a cambio de la entrega del alma. Son lugares especiales asociados a determinadas cuevas, lagunas, árboles, médanos (Escolar, 2012), pero cuya esencia excede la fisicalidad espacial. No siempre dicho espacio se encuentra activo, ni para todos. Como nos comentaron varias veces en Oyola (departamento El Alto, Catamarca), algunas fechas especiales, como el Viernes Santo, Navidad o el Día de los Muertos, habilitan el acceso a la salamanca a quienes acudan en ciertas condiciones, posean el "conocimiento" y "tengan el coraje suficiente". En estos días -continúa uno de los relatos que nos sirven de ejemplo-quien llegue por la noche a un antiguo cementerio de indios distante a unos kilómetros del pueblo podrá entrar a la salamanca, "de la mano de un sapo y con los oídos tapados para no volverse loco". Esta asociación de los restos de los indios (sitios arqueológicos) con la observación de seres no humanos y, en particular, con las salamancas, ha sido referida también para otras localidades de la sierra de El Alto-Ancasti (Rodríguez Curletto, 2008) y de diferentes puntos del país (Biasatti, 2016; Escolar, 2010; Jofré, 2011). Es interesante advertir que, en muchos de estos casos, las salamancas son también espacios con arte rupestre prehispánico, especialmente cuevas. Como mencionamos, otros abrigos con pinturas rupestres de la sierra también son indicados como salamancas. Al respecto, conviene destacar que la peligrosidad de determinadas cuevas con arte rupestre, en tanto espacios liminales de interconexión de mundos y de encuentros con seres no ordinarios, parece haber sido un fenómeno de mayor amplitud documentado en toda la región andina (Cruz, 2006).

El segundo punto que deseamos retomar se vincula a la tradicional comprensión académica de las salamancas como "mitos", "costumbres" o como parte del "folclore" y del "imaginario" local, en sintonía con las formas en que por mucho tiempo han sido interpretadas las ontologías no occidentales y las formas subalternas de ser/conocer. En ese sentido, las ontologías y epistemologías "otras", especialmente en sus relaciones con seres y eventos difícilmente comprensibles para el pensamiento moderno-occidental, han sido desacreditadas como meros artilugios del pensamiento, supercherías, y confinadas al campo de las ideologías, al mismo tiempo que fueron demonizadas y perseguidas por su raíz subversiva (Escolar, 2012). Como afirma Farberman (2005), es posible que bajo el concepto de salamancas persistan los relictos de antiguas cosmovisiones amerindias, transformadas producto de las campañas de extirpación de idolatrías desarrolladas en América desde la invasión europea. Quizás sea esta, entre otras alternativas posibles, una de las explicaciones a las tensiones evidentes entre conocimiento/ desconocimiento que surgen cada vez que el tema de las salamancas se filtra en una conversación: quienes nos cuentan de estos eventos dicen, al mismo tiempo, nunca haber asistido e, incluso, no creer en ellas. Sin embargo, como señala Escolar (2012), para quienes viven en las zonas rurales de San Juan -y también de Catamarca, agregamos- las salamancas son experimentadas y representadas como reales, con consecuencias políticas y económicas específicas. Nuestro caso de estudio, además, nos permite sumar que estos eventos extraordinarios también poseen índices materiales concretos: cuevas, peñas rocosas, médanos o espejos 
de agua, pero también pinturas, escritos de nombres, restos de huesos y velas, entre otras cosas. Esta materialidad no solo señala y atestigua la realidad de las salamancas más allá de las vicisitudes del pensamiento, sino que también las perpetúa más allá de las narraciones ocasionales.

En tercer lugar, y estrechamente conectado con lo anterior, resulta importante remarcar que las salamancas se presentan como fenómenos relevantes para las comunidades locales o, al menos, para determinados actores dentro de dichos entramados sociales inherentemente heterogéneos. ${ }^{1}$

Sería contradictorio, después del párrafo previo, indicar que dicha importancia reside en su omnipresencia en los relatos folclóricos o en los significados que poseen para las personas. Antes bien, las salamancas se erigen como los espacios/eventos reales en donde se aprenden oficios muy precisos, como la capacidad de curar a los animales y de tratar distintas enfermedades (empacho, ojeadura, pata de cabra, entre otras) y se pueden sufrir experiencias aterradoras si quien asiste a tal evento no fue invitado. Al respecto, uno de los relatos que recuperamos asociado a la salamanca de Albigasta describe la experiencia de un baqueano que, arreando mulas desde Albigasta hacia la sierra, se sentó a descansar a la orilla del río y se durmió, pero minutos más tarde se despertó sobresaltado en medio de una especie de intenso terremoto que parecía derrumbar sobre él los grandes paredones que encajonan el río. Mientras salían corriendo las mulas, tomó su puñal, hizo una cruz en un árbol y salió del lugar. Volvió pasados unos días a observar las consecuencias del derrumbe, pero todo estaba intacto, como si nada hubiera ocurrido. De tal modo, la relevancia de la salamanca no se limita al campo semántico, no es solo una forma costumbrista del decir, sino que se inmiscuye en el devenir de las formas de vida locales con consecuencias igualmente reales. En este punto, también podemos mencionar algunos comentarios recogidos durante los trabajos en la cueva de La Candelaria, otro abrigo rocoso destacado como una importante salamanca, distante a unos cuatrocientos metros del camino rural que conecta la localidad de Anquincila con La Candelaria. Según nos comentaron, por varios años, quienes transitaban a caballo entre ambos poblados escuchaban sonidos provenientes de la cueva y, en ocasiones, eran sorprendidos por una "sombra negra" que se les sentaba en el caballo a sus espaldas. Dichos sucesos desalentaban el tránsito entre ambas localidades, motivo por el cual convocaron al cura del pueblo para que fuera a bendecir la cueva y así acabar con esas angustiosas situaciones.

\section{¿Salamancas como patrimonio cultural?: dos perspectivas de un problema paradójico}

La salamanca de Albigasta y el "sitio arqueológico Salamanca de Albigasta" parecen referirse a un mismo objeto, a una misma cosa, pero ¿es el mismo objeto? ¿O ambos lugares habitan espacios yuxtapuestos encontrados? ¿Qué sucede si damos crédito o tornamos serio lo que nuestros ojos y cuerpos sintieron en aquella visita y a todo lo relatado por las personas que viven en este lugar? ¿Cómo deberíamos actuar, en tanto especialistas en arqueología o antropología social, frente a la situación hipotética de tener que conservar el sitio Salamanca de Albigasta? ¿Cuáles serían las posibles consecuencias de tales acciones? Seguramente la pluralidad de las respuestas posibles exceda los límites de este trabajo, pero aun a riesgo de simplificar el problema, deseamos rescatar lo que, entendemos, son dos perspectivas sobre la(s) salamanca(s). Aquí nuestro uso del concepto de perspectiva intenta retomar algunos desarrollos de la
1. Las referencias, ejemplos, situaciones que describimos en este trabajo fueron relatadas por diferentes personas en diversidad de situaciones, en algunos casos en entrevistas abiertas ejecutadas en el marco de programas de voluntariado universitario, particularmente cuando comentábamos sobre los lugares donde estábamos trabajando; en otras ocasiones nos comentaron cuando íbamos acompañados por algún baqueano a conocer algún sitio arqueológico o histórico que nos querían mostrar y pasábamos cerca de una salamanca; en otras, en charlas informales durante encuentros o invitaciones a asados o fiestas en casas de familia. Nuestro trabajo se desarrolla en varias localidades de la sierra, desde la zona de cumbres hasta la zona llana en el este, casi en contacto con Santiago del Estero. Las personas que nos refirieron estas situaciones son moradores de diferentes pueblos, como Vilismán, Oyola, Albigasta, La Candelaria, etc. En el caso de la salamanca de Albigasta, esta es referida y conocida en distintos lugares de la sierra; su fama trasciende la comunidad de Albigasta y se extiende a otras localidades y ciudades cercanas. 
antropología amazónica de las últimas décadas (Viveiros de Castro, 2004a, 2004b, 2010), que plantean que una perspectiva es mucho más que una visión de las cosas e implica una ontología particular del mundo. Para dichos grupos, la posible existencia de múltiples agentes -humanos y no-humanos-conlleva la posibilidad de diferentes perspectivas, y con eso, de múltiples ontologías. Al contrario, entonces, a lo que ocurre en la cosmovisión occidental-moderna, donde existe un mundo (naturaleza, objetos) y, a lo sumo, varias interpretaciones de él (culturas, ideas), para el multinaturalismo amerindio, los mundos son tantos como perspectivas existan. De esta manera, cada una de las perspectivas resumidas a continuación expresan concepciones ontológicas diferentes de la salamanca, sobre su ser, que pugnan sobre este espacio que es, según quien lo mire/use/experimente, sitio arqueológico patrimonial o un espacio/evento salamanquero.

La primera perspectiva que deseamos explorar surge al situarnos en la posición estatal/académica occidental, de acuerdo con la cual la Salamanca de Albigasta es un sitio arqueológico con arte rupestre, que debe preservarse como patrimonio material prehispánico. En esta instancia, según las recomendaciones internacionales y las leyes vigentes (Ley nacional $N^{\circ} 25.743$ y Ley provincial $\mathrm{N}^{\circ} 4218$ ) debería primar la conservación material del sitio, desalentando cualquier intento de modificación de su estado original. Es ahí cuando los especialistas en arqueología y conservación nos erigimos como encargados legales de diferenciar lo antiguo y auténtico, que debe ser protegido/conservado/ restaurado, de los agregados modernos que lo "contaminan" y deterioran, y entonces también, de los agentes que catalizan su transmutación de salamanca a sitio arqueológico y luego a patrimonio cultural. La estrecha relación entre la autenticidad de un bien cultural y su estabilidad material ha sido uno de los elementos más arraigados en la noción de patrimonio cultural (Gonçalves, 2007) y, específicamente, del patrimonio arqueológico. Este enfoque alentaría la remoción de todos los escritos y materiales "modernos" presentes en la cueva, la implementación de medidas para evitar el deterioro futuro y hasta la restauración de los motivos rupestres. De más está decir que no podremos volver el tiempo atrás, por lo cual el nuevo estado de la cueva que resulte de estas acciones, a pesar de presentarse como un retorno, sería una nueva elaboración antrópica, problemática que algunos abordajes críticos en conservación describen como "fabricación del patrimonio cultural" (Muñoz Viñas, 2005).

Al mismo tiempo, a lo largo de este proceso de conservación se deberían prohibir todas aquellas prácticas no académicas que impliquen la transformación material de la cueva, aspecto no menos importante para sus usos como salamanca. Pero entonces, ¿cómo se realizarían los nuevos pactos demoníacos sin la posibilidad de escribir los nombres, tal como lo dice el instructivo pintado en la pared? ¿Es posible estabilizar y controlar este lugar que vive en la transformación? ¿Es posible una salamanca bajo la órbita del Estado? Vale recordar aquí que, si fuera cierta la hipótesis según la cual algunas salamancas ocultas en el monte o en las cuevas resultan de la proscripción desde tiempos del coloniaje español de antiguas formas rituales como las juntas y borracheras (Grosso, 2008), entonces aquello que se debería prohibir no es sino el resultado de una prohibición previa.

Este proceso, incluso, podría culminar con la apertura del sitio a la visita turística, gestionada por el municipio o por los organismos provinciales correspondientes, tal como se insertan muchos de estos espacios patrimonializados en la posdisciplina (Haber, 2010). Como vimos, otra de las características que parecen definir a estos espacios/eventos es el carácter contrahegemónico, y 
la definición de la salamanca como bien patrimonial supondría un reconocimiento oficial. Ahora bien, ¿en qué medida estas acciones no terminarían con el carácter subversivo del lugar y, con ello, con la propia salamanca?

La perspectiva descripta asume una ontología unívoca del lugar en tanto sitio arqueológico: una cueva con arte rupestre prehispánico cuyos antiguos relictos deben conservarse para las generaciones futuras. En este enfoque patrimonial no hay lugar para otros usos y agentes no oficiales (salvo posibles turistas) ni margen para la transformación material del abrigo por fuera de los trabajos de conservación o restauración. Implícita en esta ontología subyace también una noción del tiempo occidental-moderna (Lucas, 2005; Agamben, 2007), con un sentido y una (única) dirección desde el pasado hacia el futuro, suposición que habilita a pensar al sitio como relicto presente de un pasado que solo perdura en sus vestigios materiales (Haber, 2010). Dado que es el pasado lo que se materializa en esta comprensión unívoca de la cueva o, mejor dicho, que dicha cueva es solo pasado en el presente, es que debe ser protegida de toda contaminación actual entendida como deterioro, ya sea natural o cultural.

Por otro lado, la segunda perspectiva de análisis que queremos esbozar supone centrarnos en la interrelación entre los usos locales de dicha cueva, su transformación histórica y su complejidad ontológica. Al respecto, es importante una aclaración inicial: no conocemos, en detalle, cómo son dichos usos, ni su diversidad, tan solo hemos podido comenzar a explorar algunas de sus consecuencias materiales e interconectarlas a las narraciones que hemos mantenido indirectamente sobre este tema con nuestros interlocutores. Sin embargo, dichos indicios son suficientes para sospechar de un uso activo y recurrente de este espacio, que es reconocido como una de las salamancas más importantes de la sierra y que, a juzgar por los nombres escritos en las paredes, parece haber sido objeto de estas prácticas desde hace bastante tiempo. Comprender la cueva en su dimensión histórica, es decir, considerando el derrotero de acciones y relaciones entre humanos y no humanos que le dieron forma, la transformaron y produjeron múltiples temporalidades, implica reconocer que las pinturas rupestres prehispánicas son el resultado de uno de los tantos episodios de uso de este espacio, luego sucedido por muchos otros. Al respecto, resulta interesante observar una de las fotografías procesadas con el software D-Stretch para resaltar los colores (Figura 2.d). En esta imagen se advierte -debajo, en términos estratigráficos, de los trazos negros presuntamente prehispánicos- una figura antropomorfa con sombrero, una especie de capa y un instrumento en una de sus manos (¿espada? ¿cruz?). Dicha figura se asocia a un conjunto de letras de las cuales se llega a observar parte de una palabra: "TONC". A partir de la tipografía antigua de este escrito, podemos pensar que se trata de un evento colonial, lo cual situaría las pinturas negras superpuestas en períodos posteriores a pesar de las similitudes que comparten con el repertorio rupestre prehispánico documentado en sitios próximos. A estos motivos elaborados en la cueva se habrían agregado, en las últimas décadas, la diversidad de nombres observados en las paredes. Por lo tanto, si bien quedará para futuras investigaciones indagar en la antigüedad precisa de cada conjunto de pinturas, es posible resaltar que tenemos algunas evidencias que apuntan a un uso prolongado de la cueva, quizá bajo distintas lógicas culturales. La complejidad histórica de esta cueva, con pinturas y escritos realizados en diferentes períodos temporales, nos permite sospechar de ciertas transformaciones en las prácticas sociales allí ejecutadas. Dichas modificaciones podrían corresponderse con diferentes formas de entender el mundo y la relación entre seres, aunque, por el momento, contamos con poca información sobre esas posibles ontologías. Sin embargo, las evidencias materiales 
2. Por transmutabilidad de los espacios nos referimos a aquella propiedad o cualidad de la salamanca de mutar de estado: puede presentarse o no al visitante, es decir, ser visible o invisible; de pasar de un estado a otros rápidamente, como el caso descripto del derrumbe, de la destrucción total a la calma y permanencia casi inmutable de la cueva a lo largo del tiempo. documentadas, sumadas a la información sobre salamancas registrada por otros investigadores, y en nuestras charlas con pobladores de la zona, hacen factible plantear que los usos actuales/locales de la cueva implican una ontología diferente a la supuesta en la comprensión de este espacio como sitio arqueológico, es decir, a la occidental-moderna implícita en la perspectiva descripta párrafos atrás. En ese sentido, la existencia de seres extraordinarios con los cuales se pacta mediante escritos en las paredes, la transmutabilidad de los espacios, ${ }^{2}$ la difuminación de las fronteras entre humanos-animales, entre otros aspectos que caracterizan a las descripciones de las salamancas, suponen relaciones entre seres y mundos otros. En esta ontología, la cueva parece no ser un espacio inmutable para contemplar los vestigios del pasado, sino un lugar potente de acción y transformación, dinámico, inestable, donde el cambio es la norma antes que la excepción.

Por último y en relación con el punto anterior, quizás convenga recuperar nuestra experiencia durante la visita al abrigo y los efectos que tal episodio produjo en algunos de nosotros. Esa situación afectó de manera desigual a quienes participamos de tal evento, pero en alguna medida bastó para impulsar dos consecuencias. En primer lugar, el hecho de compartir nuestras experiencias de ser afectados (Favret-Saada, 1980) en las charlas ocasionales con los pobladores de la zona, podría haber ayudado a que compartieran con nosotros parte de sus vivencias en las salamancas. En segundo lugar, ese encuentro con fenómenos extraordinarios (Escolar, 2010) puso en tensión -una vez másnuestra tradicional comprensión de las salamancas como parte de la historia oral, como una leyenda relatada por otros siempre lejana a las experiencias de investigación y a los investigadoros. Entendemos que dicho episodio nos alienta a adoptar una actitud similar a la propuesta por Viveiros de Castro (2010) para indagar en las metafísicas amerindias: más allá de si creemos o no lo que nos señalan las personas con las que interactuamos en el campo, o en los lugares donde desarrollamos nuestro oficio de arqueólogos, debemos otorgarles un viso de realidad, la posibilidad de que así sean experimentadas y aprehendidas por las poblaciones estudiadas, su posibilidad ontológica más allá de su existencia discursiva y simbólica. Esta elección intenta oponerse al monismo ontológico académico y, en nuestro caso, nos incita a entender la salamanca de Albigasta como un lugar/evento real en donde nuestras acciones de estudio y conservación pueden producir -y también ser las destinatarias de- consecuencias igualmente reales.

\section{A modo de cierre}

De forma más o menos explícita, los párrafos anteriores describen algunos de los problemas que surgen al estudiar y conservar los sitios arqueológicos, proceso mediante el cual determinados lugares y cosas son erigidos como parte del patrimonio cultural. Dichos procesos de patrimonialización (Prats, 2005), disciplinamiento (Haber, 2010), activación patrimonial (Biasatti, 2016) o gesta y gestión del patrimonio (Souza Lima, 2002), no implican el reconocimiento de un estado innato previo de los bienes, sino más bien su transformación ontológica en sitios y objetos arqueológicos, con las consiguientes modificaciones en el tipo de relaciones y prácticas sociales prescriptas y proscriptas. Tales transformaciones, mencionadas como parte de la primera perspectiva descripta, no descansan únicamente en el plano semántico, sino que tienen consecuencias materiales igualmente importantes, como la limpieza de todo agregado "moderno" que distorsione el estado prístino a conservar (Pellini, Marconetto y Gheco, en prensa). Estas modificaciones distan de ser actitudes 
neutrales y universales y, al contrario, expresan (y reproducen) una particular forma de relacionarse con los seres, cosas, tiempos y espacios característica de la ontología occidental-moderna.

La segunda perspectiva, por otro lado, pone en tensión el monismo ontológico occidental-moderno que comprende esta cueva únicamente como un sitio arqueológico. De este modo, ya sea retomando nuestras experiencias de afección o bien dando crédito a los comentarios recogidos en las charlas con los pobladores de la zona, la salamanca se presenta como un lugar potente e inestable que excede los contornos físicos y guarda peligros para quienes lleguen sin los recaudos adecuados, pero también posibilidades para aquellos "con el coraje suficiente".

En vista de esas dos perspectivas en gran medida contrapuestas, por último, retomemos el interrogante inicial: ¿es posible conservar la salamanca de Albigasta? Dicha consigna no hace más que llevar al extremo una tensión que subyace en muchos casos en que los estudios arqueológicos y las actividades de conservación/restauración patrimonial se intersectan con usos y comprensiones otras de dichos espacios. A partir de lo reseñado páginas atrás, esa pregunta se asemeja a un oxímoron, un interrogante contradictorio que nos impulsaría a responder rápidamente por la negativa: no, no es posible conservar la cueva con arte rupestre y, al mismo tiempo, la salamanca. Ahora bien, tal respuesta nos incita a optar por "sitio arqueológico" o por "salamanca", por uno u otro lado de la dicotomía, haciéndonos trastabillar nuevamente con el problema de las respuestas unívocas. Pero ¿existen márgenes para la cohabitación de perspectivas? ¿Podrían coexistir el sitio arqueológico y la salamanca? Varios casos a nivel nacional e internacional nos permiten sospechar que existen espacios de negociación, disputa y convivencia entre perspectivas patrimoniales hegemónicas y subalternas (Escolar, 2003; Van der Spek, 2011; Marconetto, 2021; Pellini, Marconetto y Gheco, 2021). Marconetto (2021), por ejemplo, describe la importancia que posee para las mujeres egipcias el tocar determinados jeroglíficos en los grandes (y turísticos) templos faraónicos de Lúxor, declarados patrimonio de la humanidad hace varias décadas, aunque dicha actividad sea penada por la legislación vigente. Más cerca en términos geográficos, Escolar (2003) menciona los usos actuales de las "casas de piedra", antiguas cuevas con arte rupestre y/o enterratorios indígenas, por parte de los arrieros en San Juan. De manera similar, en la sierra de El Alto-Ancasti documentamos una cueva con arte rupestre prehispánico en Oyola denominada "Casa del Cura", en cuyas paredes también se advierten inscripciones y marcas de ganado de principios de siglo XX (Quesada y Gheco, 2015) y en donde, por los comentarios de los pobladores actuales, se daba catequesis hasta hace algunas décadas $\mathrm{y}$, luego, vivió una familia "hippie" por varios años. En otra cueva con arte rupestre de la zona, en La Candelaria, la visita turística del sitio parece coexistir con la realización de rituales new age y con el carácter de salamanca del abrigo. Por último, la activación patrimonial del sitio arqueológico Pueblo Perdido de la Quebrada, también en Catamarca, habilitó la práctica de sentidos inesperados en la planificación original, como los rituales a la Pachamama, "satánicos", casamientos y consumo de infusiones de cactus (Barrionuevo y Nagel, 2014). Los ejemplos podrían continuar, sin embargo, bastan para exponer la posibilidad de coexistencia de perspectivas hegemónicas y contrahegemónicas en los espacios patrimonializados; entornos donde se mezclan lo sagrado y lo profano; lo promovido, lo tolerado y lo prohibido; las prácticas locales y el patrimonio estatizado. 
En este punto, creemos necesario explicitar la perspectiva patrimonial que nos interpela y las complejidades que dicho concepto acarrea. Gonçalves (2007) plantea que, como toda clasificación, el patrimonio encierra contradicciones; mientras que el Estado identifica a un grupo y su patrimonio, ejerce su función de agencia de poder dando visibilidad a lo que cree que tal patrimonio representa y silencia o invisibiliza a todo aquello que no entra en dicho sistema clasificatorio, pero que, a su vez, queda libre de ese control. Es justamente allí, en dicha paradoja, donde radica la fuerza de la noción de patrimonio; no como expresión de identidades dadas de una vez y para siempre (limitado a la tarea de descubrir, defender, rescatar y preservar dichas identidades y las cosas que las materializan), sino como formas de autoconciencia individual y colectivas siempre disponibles a disputar nuevos sentidos (Gonçalves, 2007).

De regreso a nuestro caso, el sitio arqueológico o el evento salamanquero no son escindibles, de la misma manera que no es posible separar la experiencia de las personas hecha discurso, hecha cuerpo, hecha materia con el sitio/salamanca. Al respecto, en un ensayo de 1933, Walter Benjamin (1987) se preguntaba: “¿Cuál es el valor de todo nuestro patrimonio cultural, si la experiencia ya no nos une a él?" (p. 196). En una perspectiva identificada como "crítica de la cultura", el autor señaló la "pérdida de la experiencia" como característica de la modernidad. Sin embargo, es posible que, si concebimos los patrimonios desde un punto de vista etnográfico, si abrimos esta categoría y exploramos sus otras dimensiones, podamos encontrar formas de patrimonio cultural en el mundo contemporáneo que están fuertemente vinculadas a la experiencia, con los efectos y afectos. Esta dimensión está en permanente tensión con la otra, oficial y estatizada, pero no por eso dejan de coexistir. Las variaciones de significado en las representaciones sobre la categoría patrimonio oscilan, posiblemente, entre los patrimonios entendidos como parte y extensión de la(s) experiencia(s), y por tanto del(os) cuerpo(s), y un patrimonio entendido de forma objetivada, externa, neutra, innata y unívoca. Como vimos a través del ejemplo de la salamanca de Albigasta, muchos sitios arqueológicos son más que esto último y encierran complicados entramados de actores, tiempos y ontologías. Anclarnos en una de las perspectivas implica, necesariamente, recortar $\mathrm{u}$ omitir una de las partes de este lugar/evento multidimensional. Y en esa acción, el peligro de una sola historia es la simplificación de la(s) experiencias(s); una sola historia crea estereotipos, y el problema con estos muchas veces no es que sean falsos, sino que son incompletos (Chimamanda Adichie, 2009). Para este trabajo, entonces, nos quedamos con esa reflexión: la salamanca, al igual que la memoria y los patrimonios, no pueden aprehenderse en singular.

Pasaron varios años desde aquella visita a la salamanca de Albigasta y aún no volvimos. No sabemos bien por qué; si por respeto ante lo desconocido, cierto temor o, sobre todo, porque la perplejidad de haber sido afectados nos atraviesa al momento de decidir si debemos continuar este trabajo y, fundamentalmente, cómo hacerlo. ¿Qué estrategias metodológicas podríamos utilizar para abordar un caso de estudio que trastoca o desestabiliza la relación sujeto-objeto tal cual la conocemos? ¿Hasta qué punto inmiscuirnos en este lugar/evento si no tenemos muy en claro cuáles serían las consecuencias de nuestras acciones, para nosotros, aquellos con quienes interactuamos y para la salamanca?

Nuestro primer encuentro con ella no fue del todo amigable; de alguna forma, durante un lapso de tiempo corto, pero intenso, primó su perspectiva. La salamanca develó una parte de su intencionalidad, se nos hizo presente en un 
modo que nos dejó claro que no éramos del todo bienvenidos. En ese momento, el sitio arqueológico "Salamanca de Albigasta", espacio ontológico donde los arqueólogos desplegamos nuestros poderes de observación y aprensión de la realidad, se borró, quedo como a un costado de nuestra percepción; de hecho, al primar su perspectiva, quizás nos encontramos en otro mundo, parecido al nuestro, pero diferente, donde las reglas son otras, donde las cámaras de fotos y sus mecanismos basados en leyes de nuestro mundo no funcionan. $\mathrm{Si}$ retomáramos aquella definición de la salamanca como lugar de aprensión de conocimientos o universidad de los indios, quizás dicha intencionalidad, dicho desplazamiento ontológico, tuvo sus efectos de conocimiento sobre nosotros y el modo de conocer que venimos implementando en estos lugares.

Viveiros de Castro (2004b) señalaba sobre el modo de conocer amerindio, particularmente sobre los shamanes, que conocer no es objetivar, no se trata de transformar algo en objeto de estudio para analizar sus partes, componentes, proceso de producción, etc., sino más bien que lo que se quiere conocer revele un máximo de intencionalidad, de tal modo de encontrar un lenguaje común que haga posible la comunicación. Teniendo en cuenta esto, quizás el encuentro con la salamanca de Albigasta nos esté marcando cierto camino a seguir: no se trata solo de conocer un sitio arqueológico, sino de entablar relaciones, de ser invitado, de pedir permiso y, sobre todo, de no obviar su potencia. En este punto, las palabras de advertencia sobre la peligrosidad, la necesidad de ir "leído" o "estudiado" para saber "las respuestas", el ser corajudo conociendo las pruebas a las que seremos sometidos al ir a la salamanca, cobran otro sentido. Este trabajo, creemos, es ese primer paso para comenzar entablar un nuevo diálogo, diferente, con los espacios donde trabajamos y con aquellas personas que, desde hace mucho tiempo, vienen relacionándose con ellos.

\section{Financiamiento}

Este trabajo fue ejecutado gracias al financiamiento de los proyectos PICT 2017-2462, PICT 2017-2589 y PICT 2019-4113 dirigidos por Lucas Gheco, Marcos Quesada y Marcos Gastaldi respectivamente. Del mismo modo, contamos con el financiamiento de la Secretaría de Ciencia y Técnica de la Universidad Nacional de Catamarca (Proyecto $02 / J 278)$.

\section{Agradecimientos}

Este trabajo fue posible gracias a la colaboración de los integrantes del Equipo Interdisciplinario El Alto-Ancasti. Deseamos agradecer también a Bernarda Marconetto y Pablo Cruz por los importantes comentarios y sugerencias al momento de escribir el texto original. Gran parte de este trabajo es el resultado de las charlas con los pobladores de las distintas localidades de la sierra de El Alto-Ancasti, a quienes agradecemos por la ayuda y predisposición. Por último, este artículo fue posible gracias al financiamiento de la Agencia Nacional de Promoción de la Investigación, el Desarrollo Tecnológico y la Innovación, y de la Secretaría de Ciencia y Técnica de la Universidad Nacional de Catamarca.

\section{Biografía}

Lucas Gheco es investigador asistente de CONICET y profesor adjunto de la Licenciatura en Conservación y Restauración del Patrimonio Cultural (EAyP, UNSAM). En el año 2012 obtuvo el grado de licenciado en Arqueología (EdA, UNCa), y en 2017, el título de doctor en Ciencias Antropológicas (FFyH, UNC). 
Melisa Rodríguez Oviedo es licenciada en Antropología, doctoranda en Ciencias Antropológicas de la Facultad de Filosofía y Humanidades, becaria doctoral del IDACOR - CONICET. Actualmente se encuentra realizando investigaciones en torno a patrimonio y memoria desde una mirada local en el Museo de Antropología de la Universidad Nacional de Córdoba.

Marcos Gastaldi es investigador adjunto de CONICET y profesor adjunto de la Licenciatura en Antropología de Facultad de Filosofía y Humanidades (UNC). Obtuvo el grado de licenciado en Arqueología en 2002 (EdA, UNCa) y de doctor en Ciencias Naturales en 2010 (FCNyM-UNLP). Es miembro del consejo directivo del Instituto de Antropología de Córdoba.

Marcos Quesada es investigador independiente de CONICET y profesor adjunto de la Licenciatura en Arqueología de la Escuela de Arqueología (UNCa). Obtuvo el grado de licenciado en Arqueología en 2001 (EdA, UNCa) y de doctor en Ciencias Naturales en 2007 (FCNyM-UNLP). 


\section{Q Referencias bibliográficas}

Adichie, C. N. (2009). Chimamanda Adichie: El peligro de la historia única. TED Talks. Recuperado de https://bit.ly/3iBGoBz

" Agamben, G. (2007). Infancia e historia. Destrucción de la experiencia y origen de la historia. Madrid: Adriana Hidalgo.

" Barrionuevo, M. D. y A. Nagel (2014). Múltiples perspectivas en torno a la apropiación social de un sitio arqueológico: Pueblo Perdido de la Quebrada como espacio de reflexión. Primeras Jornadas Regionales y Terceras Jornadas Internas de Antropología. Salta, Argentina

" Bendix, R. (2009). Heritage between economy and politics: An assessment from the perspective of Cultural Anthropology. En L. Smith y N. Akagawa (Eds.), Intangible Heritage (pp. 253-269). Londres: Routledge.

» Benjamin, W. (1987). Magia e técnica, arte e política. Obras escolhidas, vol. 1. San Pablo: Brasiliense.

" Biasatti, S. (2016). Arqueología e identidades: Procesos de integración sociocultural del patrimonio arqueológico (Provincia de San Juan). Córdoba: Universidad Nacional de Córdoba.

" Bocelli, S. (2016). Motivos para dibujar la roca: Un primer acercamiento al arte rupestre de La Aguadita (Tapso, Catamarca). Comechingonia, 20(2), $105-126$.

»Cruz, P. (2006). Mundos permeables y espacios peligrosos. Consideraciones acerca de punkus y qaqas en el paisaje altoandino de Potosí, Bolivia. Boletín del Museo Chileno de Arte Precolombino, 11, 35-50.

»De la Fuente, N. (1979). Arte rupestre en la región de Ancasti, Prov. de Catamarca. Antiquitas, 2, 408-418.

»De la Fuente, N. y Arrigoni, G. (1975). Arte rupestre en la Región Sudeste de la provincia de Catamarca. Actas del Primer Congreso Nacional de Arqueología Argentina, 177-203.

" De la Fuente, N., Nazar, D. C. y Pelli, E. (2005). Documentación y diagnóstico del arte rupestre de La Tunita, Provincia de Catamarca, República Argentina. En S. Martin, M. E. Gonaldi, S. Ferraris y A. Giordano (Eds.), La Cultura de La Aguada y sus Expresiones Regionales (pp. 227-244). La Rioja: EUDELAR.

»Escolar, D. (2003). Arqueólogos y brujos: La disputa por la imaginación histórica en la etnogénesis huarpe. Relaciones de la Sociedad Argentina de Antropología, 28, 23-43.

»Escolar, D. (2010). "Calingasta x-file”: Reflexiones para una antropología de lo extraordinario. Intersecciones en Antropología, 11, 295-308.

"Escolar, D. (2012). El vórtice soberano: Salamancas, políticas de lo extraordinario y la emergencia de los huarpes en Cuyo, Argentina. Nuevo Mundo, Mundos Nuevos. doi: https://doi.org/10.400o/nuevomundo.64570

" Farberman, J. (2005). Las salamancas de Lorenza. Ciudad Autónoma de Buenos Aires: Siglo XXI.

"Favret-Saada, J. (1980). Deadly words: Witchcraft in the Bocage. Cambridge: Cambridge University Press. 
"Gheco, L. (2017). El laberinto de las paredes pintadas. Una historia de los abrigos con arte rupestre de Oyola, Catamarca [Tesis de Doctorado no publicada], Facultad de Filosofía y Humanidades, Universidad Nacional de Córdoba, Argentina.

» Gheco, L. (2020). Una aproximación histórica al arte rupestre prehispánico de la sierra de El Alto-Ancasti (Provincia de Catamarca, Noroeste Argentino). Estudios Atacameños. Revista de Arqueología y Antropología Surandinas, 65, 263-290.

» Gonçalves, J. R. S. (2007). Antropologia dos objetos: Coleções, museus e patrimônio. Museu, memoria e ciudadania.

» González, A. R. (1998). Cultura La Aguada. Arqueología y diseños. Filmediciones Valero.

» Gordillo, I., Zuccarelli, V. y Eguía, L. (2017). Las casas del sol naciente. Arqueología de la vertiente oriental de El Alto-Ancasti. En B. Ventura, G. Ortiz y M. B. Cremonte (Eds.), Arqueología de la vertiente oriental Surandina (pp. 111-130). Ciudad Autónoma de Buenos Aires: Sociedad Argentina de Antropología.

"Gramajo, A. (2001). Solar de mis mayores. La concepción del Alto. Santiago del Estero: Ediciones $\mathrm{V}$ centenario.

» Gramajo, A., y Martínez Moreno, H. (1978). Otros aportes al arte rupestre del este Catamarqueño. Antiquitas, 26-27, 12-17.

» Gramajo, A. y Martínez Moreno, H. (1982). Otros aportes al arte rupestre del este catamarqueño. Estudio. Museo Arqueológico Emilio y Duncan Wagner, 3, 77-88.

»Grosso, J. L. (2008). Indios muertos, negros invisibles. Hegemonía, identidad y añoranza. Córdoba: Encuentro Grupo Editor

» Haber, A. (2010). El patrimonio arqueológico ha muerto. Un epílogo y un epitafio. En I. C. Jofré (Ed.), El regreso de los muertos y las promesas del oro: Patrimonio arqueológico en conflicto (pp. 255-263). Córdoba: Encuentro Grupo Editor.

» Hedges, R. E. M., Ramsey, C. B., Klinken, G. J. V. A. N., Nielsen, C., Etchegoyen, A., Niello, J. D. F., Boschin, M. T. y Llamazares, A. M. (1998). Methodological issues in the ${ }_{14} \mathrm{C}$ dating of rock paintings. 16th International ${ }_{14}$ C Conference. Radiocarbon, 40(1), 35-44.

" Jofré, I. C. (2011). Riquezas que penan, hombres oscuros y mujeres pájaro entre "las cosas de indios": Relaciones "otras" asechando los sentidos de la experiencia moderna en el norte de San Juan, República Argentina. Jangwa Pana. Revista del Programa de Antropología de La Facultad de Humanidades, 10, 68-96.

»Llamazares, A. M. (1999). Arte rupestre de la cueva de La Candelaria, Provincia de Catamarca. Publicaciones de Arqueología, 50, 1-26.

» Lucas, G. (2005). The Archaeology of time. Londres: Routledge.

» Marconetto, M. B. (2021). Los templos y las manos. Fertilidad, Arqueología y comunidad en Lúxor (República Árabe de Egipto). Revista del Museo de Antropología. En prensa

» Muñoz Viñas, S. (2005). Contemporary theory of conservation. Oxford: Elsevier.

»Nazar, D. C., De la Fuente, G. y Gheco, L. (2014). Entre cebiles, cuevas y pinturas. Una mirada a la estética antropomorfa del arte rupestre de La Tunita, Catamarca, Argentina. Boletín del Museo Chileno de Arte Precolombino, 19(1), 37-51.

» Nazar, D. C., Gheco, L., y Barot, C. (2012). Avances en la documentación del sitio La Tunita (Catamarca, Argentina). Comechingonia, 16, 299-308.

»Pellini, J., Marconetto, B. y Gheco, L. (2021). How to avoid the trick? Heritage discussions from Theban Tomb TT123, Luxor (Egypt). Current Anthropology. En prensa. 
" Prats, L. (2005). Concepto y gestión del patrimonio local. Cuadernos de Antropología Social, 21, 17-35.

»Quesada, M. y Gheco, L. (2011). Modalidades espaciales y formas rituales. Los paisajes rupestres de El Alto-Ancasti. Comechingonia, 15, 63-83.

"Quesada, M. y Gheco, L. (2015). Tiempos, cuevas y pinturas. Reflexiones sobre la policronía del arte rupestre de Oyola (Provincia de Catamarca, Argentina). Relaciones de la Sociedad Argentina de Antropología, 40(2), 455-476.

» Quesada, M., Zuccarelli, V., Gheco, L., Gastaldi, M. y Boscatto, S. (2016). Paisaje y experiencia en Oyola a finales del primer milenio D.C. (Dpto. El Alto, Catamarca). Comechingonia, 20(2), 13-42.

" Rodríguez Curletto, S. (2008). Procesos de construcción de identidades locales en torno al pasado prehispánico y estrategias de conservación para las representaciones rupestres del sitio arqueológico Ampolla 1 (Dpto. Santa Rosa, Catamarca). Tucumán: Universidad Nacional de Tucumán.

"Schobinger, J.y Gradin, C. (1983). Arte rupestre de la Argentina. Cazadores de la Patagonia y agricultores andinos. Madrid: Ediciones Encuentro.

"Segura, Á. (1971). Pictografías de Catamarca. Separata de la revista de la Junta de Estudios Históricos de Catamarca, 1962-1968.

"Segura, Á. (1988). El arte rupestre del este de Catamarca. Las pictografías de la Candelaria. Dpto. Ancasti, Provincia de Catamarca. Catamarca: Universidad Nacional de Catamarca.

» Smith, L. (2011). El "espejo patrimonial”. ¿llusión narcisista o reflexiones múltiples"? Antípoda. Revista de Antropología y Arqueología, 12, 39-63

»Souza Lima, A. C. de (Ed.). (2002). Gestar e gerir: Estudos para uma antropologia da administração pública no Brasil. Relume Dumará : Núcleo de Antropologia da Política.

"Van der Spek, K. (2011). The modern neighbors of Tutankhamun: History, life, and work in the villages of the Theban West Bank. El Cairo: The American University in Cairo Press. doi: https://doi.org/10.16309/j.cnki.issn.1007-1776.2003.03.004

"Viveiros de Castro, E. (2004a). Exchanging perspectives. Common knowledge, 10, 463-484.

"Viveiros de Castro, E. (2004b). Perspectivismo y multinaturalismo en la América indígena. En A. Surrallés y P. García Hierro (Eds.), Tierra adentro. Territorio indígena y percepción del entorno (pp. 37-79). Copenhague: IWGIA. Documento $\mathrm{N}^{\circ} 39$.

》Viveiros de Castro, E. (2010). Metafísicas caníbales. Líneas de antropología postestructural. Ciudad Autónoma de Buenos Aires: Katz. 
